\title{
Overall readmissions and readmissions related to dehydration after creation of an ileostomy: a systematic review and meta-analysis
}

\author{
I. Vogel ${ }^{1,2}$ (1) $\cdot$ M. Shinkwin ${ }^{2}$ S. L. van der Storm ${ }^{1} \cdot$ J. Torkington $^{2} \cdot$ J. A.Cornish ${ }^{2} \cdot$ P. J. Tanis ${ }^{1} \cdot$ R. Hompes ${ }^{1}$. \\ W. A. Bemelman ${ }^{1}$
}

Received: 27 October 2021 / Accepted: 18 January 2022 / Published online: 22 February 2022

(c) The Author(s) 2022

\begin{abstract}
Background Hospital readmissions after creation of an ileostomy are common and come with a high clinical and financial burden. The aim of this review with pooled analysis was to determine the incidence of dehydration-related and all-cause readmissions after formation of an ileostomy, and the associated costs.

Methods A systematic literature search was conducted for studies reporting on dehydration-related and overall readmission rates after formation of a loop or end ileostomy between January 1990 and April 2021. Analyses were performed using R Statistical Software Version 3.6.1.

Results The search yielded 71 studies ( $n=82,451$ patients). The pooled incidence of readmissions due to dehydration was $6 \%$ (95\% CI 0.04-0.09) within 30 days, with an all-cause readmission rate of 20\% (CI 95\% 0.18-0.23). Duration of readmissions for dehydration ranged from 2.5 to 9 days. Average costs of dehydration-related readmission were between $\$ 2750$ and $\$ 5924$ per patient. Other indications for readmission within 30 days were specified in 15 studies, with a pooled incidence of 5\% (95\% CI 0.02-0.14) for dehydration, 4\% (95\% CI 0.02-0.08) for stoma outlet problems, and 4\% (95\% CI 0.02-0.09) for infections. Conclusions One in five patients are readmitted with a stoma-related complication within 30 days of creation of an ileostomy. Dehydration is the leading cause for these readmissions, occurring in $6 \%$ of all patients within 30 days. This comes with high health care cost for a potentially avoidable cause. Better monitoring, patient awareness and preventive measures are required.
\end{abstract}

Keywords Ileostomy $\cdot$ Readmission $\cdot$ Dehydration $\cdot$ High output stoma

\section{Introduction}

Hospital readmissions after creation of an ileostomy are common and impede patient convalescence [1]. Reasons for readmission after fecal diversion include stoma-related problems, such as dehydration, stoma outlet obstruction, peristomal skin problems, anastomotic leak, and generic post-operative complications (e.g., infection or thromboembolic events).

Dehydration is often cited as a leading cause for stomarelated readmissions, due to fluid and electrolyte losses [2]. Dehydration can contribute to substantial post-operative

I. Vogel

i.vogel@amsterdamumc.nl

1 Department of Surgery, G4, University of Amsterdam, P.O. Box 22660, 1100DD Amsterdam, The Netherlands

2 Department of Colorectal Surgery, Cardiff \& Vale University Health Board, Cardiff, UK morbidity, increasing the risk of acute renal failure, electrolyte derangement, and even cardiac arrhythmias [3]. There is a growing consensus that these readmissions place a significant burden on patients and are costly for the healthcare system, but that they might also be avoidable to some extent [4-6].

The reported incidence of readmission particularly in relation to dehydration varies [6-8], probably due to inconsistent definitions, and completeness and duration of postoperative follow-up. To quantify the risks and benefits of an ileostomy, to reduce stoma-related readmissions, and to guarantee patient safety, the scope of the problem needs to be clear. Therefore, the aim of this systematic review was to assess the prevalence of readmission related to dehydration after the creation of an ileostomy. The secondary aims included overall readmissions and their causes after creation of an ileostomy as well as cost implications. 


\section{Materials and methods}

This review was conducted in line with the Cochrane Handbook for systematic reviews of In Reporting following the Preferred Reporting Items for Systematic Reviews and Meta-Analyses (PRISMA) and the Meta-analysis Of Observational Studies in Epidemiology (MOOSE) guidelines [9]. The study protocol was registered in PROSPERO, the international prospective register of systematic reviews (registration number CRD42021231472). Comprehensive literature searches were conducted using PubMed, Embase, and Cochrane databases for articles published from January 1990 until April 2021. The full search strategy is displayed in Supplementary Table S1-3.

Studies were considered for inclusion if they met the following criteria: (1) patients with a newly created loop or end ileostomy for any indication; (2) assessment of readmissions related to dehydration, or overall number of readmissions, or other reasons for readmission after creation of an ileostomy; (3) studies were cohort, case-matched studies, or randomized clinical trials. The exclusion criteria were: (1) reviews, letters, expert opinions, commentaries, case reports, or case series with less than 10 cases; (2) language other than English; (3) lack of the sufficient data or outcomes of interest; (4) visits just to the emergency department; (5) studies reporting only on complications of revised ileostomies (with exception of readmissions for a revision of a newly created ileostomy); (6) second stage ileostomies in a three-stage ileo-anal pouch procedure; (7) colostomies, jejunostomies, non-intestinal stomas, and ghost ileostomies; (8) duplicate studies.

Two reviewers (IV and MS) independently reviewed titles and abstracts, followed by full-text revision. Disagreements were resolved by consensus discussion between the two reviewers (IV and MS).

\section{Data extraction and quality assessment}

Data were extracted independently by two authors (IV and MS) and included the following variables: year of publication, country, study design, number of patients, characteristics of included patients, indication for the ileostomy, type of surgery, number of elective procedures, number of open procedures, type of stoma (loop/end), overall number of readmissions, number of readmissions related to dehydration, other reasons for readmissions, duration, and cost of readmissions related to dehydration.

The indications for an ileostomy were recorded and were classified as colorectal disease if they included bowel cancer, inflammatory bowel disease, diverticulitis, or familiar adenomatous polyposis.
Readmissions were defined as an unplanned return to the hospital with an overnight stay for any reason. This did not include elective or planned readmissions.

The following were accepted as readmission related to dehydration: a clinician-reported diagnosis of dehydration, or high output stoma (defined as $\geq 1500 \mathrm{~mL}$ stoma production in $24 \mathrm{~h}$, or the Kidney Disease Global Improving guideline definition of acute kidney injury which includes any of the following: absolute increase in serum creatinine $\geq 0.3 \mathrm{mg} / \mathrm{dL}$ in a 48 -h period, 1.5 -fold increase in serum creatinine level in a 48 -h period, or oliguria of $\leq 0.5 \mathrm{~mL} / \mathrm{kg}$ for $\geq 6 \mathrm{~h}[10,11]$.

Readmissions for infection included all pathology (such as chest infections and urinary tract infections). It did not include anastomotic leaks, which were reported separately.

Whilst the primary outcome was readmission within 30 days related to dehydration after creation of an ileostomy readmission for other timeframes was also summarised. Secondary outcomes included number of all-cause readmissions, other common indications for readmission, duration, and cost associated with readmission.

All included studies were assessed for methodological quality and risk of bias. For cohort studies, the Newcastle Ottawa quality assessment scale was used to assess risk of bias [12]. For randomized controlled trials, the Jadad scoring system was used [13]. When the randomized controlled trials (RCTs) groups were not analysed as described in the RCT, the Newcastle Ottawa quality assessment was used. Two of the authors (IV and MS) performed the quality assessment, with discussion of conflicts to achieve consensus.

\section{Statistical analysis}

Quantitative analysis was performed using RStudio (R Software version 3.6.1-@2009-2012, RStudio, Inc. software) with a random-effects model. For the outcome measures, pooled weighted proportions with corresponding 95\% CIs were calculated using inversed variance weighting. Heterogeneity was assessed using the $I^{2}$ and $\tau^{2}$ statistics, and the data were considered significant if the $p$ value $\left(\tau^{2}\right)$ was $<0.1$ with low, moderate, and high for $I^{2}$ values of $25 \%, 50 \%$, and $75 \%$.

\section{Results}

In total, 3508 articles were screened on title and abstract, with 3143 articles not meeting our inclusion criteria. A further 294 studies were excluded after full-text review leaving 71 studies ( 82,451 patients) for analysis, with 62 studies able to be included in a quantitative meta-analysis (Fig. 1). The assessment for methodological quality and risk of bias is described in Table 1. 


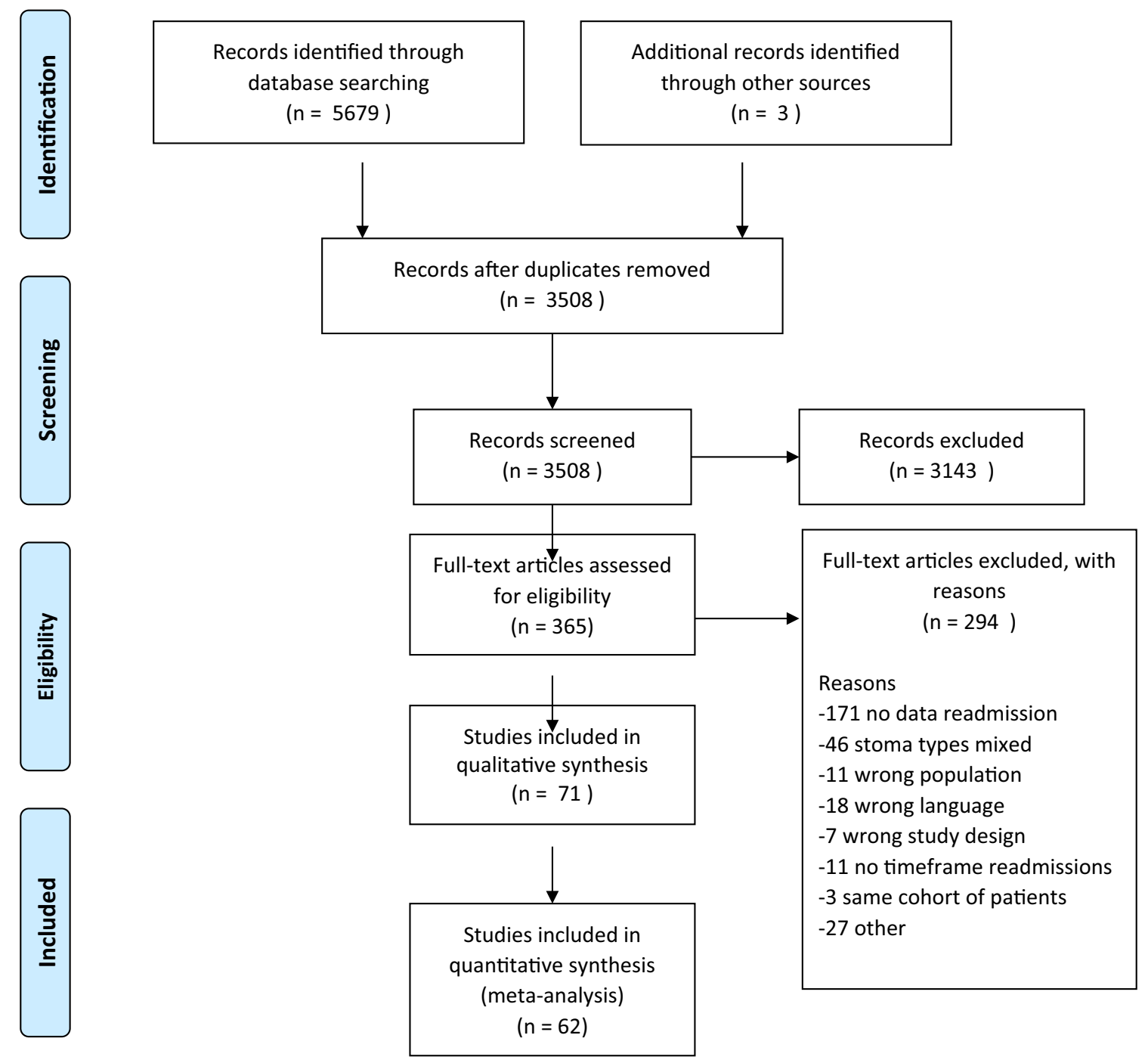

PRISMA = Preferred Reporting Items for Systematic Reviews and Meta-Analyses

Fig. 1 PRISMA flow diagram

\section{Study characteristics}

Baseline characteristics of the studies are summarised in Table 2. All patients received a newly created loop or end ileostomy. Indications for an ileostomy varied widely from colorectal cancer, inflammatory bowel disease, diverticulitis, familiar adenomatous polyposis, and gynecological malignancies, to any other indication for an ileostomy. Elective/emergency intention was reported in 42 studies, with the majority of patients included (76.9\%) undergoing elective surgery $[1-4,7,11,14-49]$. Thirty-six studies reported method of access; in $41.9 \%$ stoma creation was carried out with an open approach $[3,8,11,14-17,19,20$, $22,25,28,31,32,34-39,42,43,45,46,49-59]$.

\section{Readmission within 30 days}

A total of 46 studies reported on readmission within 30 days of ileostomy creation $[1,2,4-8,11,14-21,23,25,26$, 28-31, 33, 34, 36-38, 41-46, 52-55, 58, 60-66]. For those studies specifying readmission related to dehydration, the pooled incidence was $6 \%$ (95\% CI $0.04-0.09, I^{2}=98 \%$, $\left.\tau^{2}=1.33 p<0.01\right)$, Fig. $2[1,2,6-8,11,16,18-20,23,25$, $26,33,37,41,42,44-46,54,55,58,60,61,63-66]$. For those studies reporting overall readmission rate, the pooled incidence was $20 \%$ (CI 95\% 0.18-0.023, $I^{2}=96 \%, \tau^{2}=0.16$ $p<0.01)$, Fig. $3[1,2,4,5,7,11,14,15,17-21,23,25,26$, 28-31, 33, 34, 36-38, 41, 43-46, 52-55, 58, 60-64, 66]. For the studies assessing both overall and dehydration-related 
Table 1 Assessment for methodological quality and risk of bias

\begin{tabular}{|c|c|c|c|c|c|c|}
\hline \multirow[t]{2}{*}{ Author } & \multirow[t]{2}{*}{ Country } & \multirow{2}{*}{$\begin{array}{l}\text { Jadad score } \\
\text { Total }\end{array}$} & \multirow{2}{*}{$\begin{array}{l}\text { Newcastle quality } \\
\text { Selection (0-4) }\end{array}$} & \multicolumn{3}{|c|}{ Ottawa assessment } \\
\hline & & & & $\begin{array}{l}\text { Comparability } \\
(0-2)\end{array}$ & Outcome $(0-3)$ & Total (0-9) \\
\hline Van Loon 2020 & US & & $* * *$ & $*$ & $* *$ & 6 \\
\hline Lee 2020 & Korea & & $* * *$ & $*$ & $* *$ & 6 \\
\hline Liu 2020 & New Zealand & & $* * *$ & $*$ & $* *$ & 6 \\
\hline Kim 2020 & US & & $* * *$ & $*$ & $* * *$ & 7 \\
\hline Yaegasgi 2019 & Japan & & $* * *$ & $* *$ & $* *$ & 7 \\
\hline Hendren 2019 & USA & & $* *$ & $*$ & $* *$ & 5 \\
\hline Schineis 2019 & Germany & & $* * *$ & $*$ & $* *$ & 6 \\
\hline Grahn 2019 & US & 6.5 & & & & \\
\hline Fielding 2019 & UK & & $* *$ & $*$ & $* *$ & 5 \\
\hline Alqahtani 2019 & USA & & $* * *$ & $*$ & $* *$ & 6 \\
\hline Karjalainen 2019 & Finland & & $* * *$ & $*$ & $* *$ & 6 \\
\hline Lee J 2019 & Mexico & & $* * *$ & $* *$ & $* *$ & 7 \\
\hline Gonella 2019 & Italy & & $* * *$ & $* *$ & $* *$ & 7 \\
\hline Chen 2018 & USA & & $* * *$ & $* *$ & $* * *$ & 8 \\
\hline Justinianio 2018 & USA & & $* * *$ & $* *$ & $* * *$ & 8 \\
\hline Sier 2018 & The Netherlands & 6.5 & & & & \\
\hline Charak 2018 & US & & $* * *$ & $*$ & $* *$ & 6 \\
\hline Kandagatla 2018 & US & & $* * *$ & $* *$ & $* *$ & 7 \\
\hline Bednarski 2018 & US & & $* * * *$ & $*$ & $* * *$ & 8 \\
\hline Park 2018 & Sweden & & $* * *$ & $*$ & $* *$ & 6 \\
\hline Migdanis 2018 & Greece & 6.5 & & & & \\
\hline Iqbal 2018 & US & & $* * *$ & $*$ & $* *$ & 6 \\
\hline Wen 2017 & US & & $* * *$ & $*$ & $* *$ & 6 \\
\hline Shaffer 2017 & US & & $* *$ & & $* *$ & 4 \\
\hline Yin 2017 & Taiwan & & $* * *$ & $* *$ & $* *$ & 7 \\
\hline Li L 2017 & US & & $* *$ & $*$ & $* *$ & 5 \\
\hline Fish 2017 & US & & $* *$ & $*$ & $* *$ & 5 \\
\hline Iqbal 2017 & US & & $* * *$ & $*$ & $* *$ & 6 \\
\hline Shwaartz 2017 & US & & $* * *$ & $*$ & $* *$ & 6 \\
\hline LI W 2017 & US & & $* * * *$ & $*$ & $* *$ & 6 \\
\hline Shah 2017 & US & & $* * *$ & $*$ & $* *$ & 6 \\
\hline Hawkins 2016 & US & & $* * * *$ & $*$ & $* *$ & 7 \\
\hline Tseng 2016 & US & & $* * * *$ & $* *$ & $* *$ & 8 \\
\hline Helavirta 2016 & Finland & & $* * *$ & $*$ & $* *$ & 6 \\
\hline Anderin 2016 & Sweden & & $* * *$ & $*$ & $* *$ & 6 \\
\hline Kulaylat 2015 & US & & $* *$ & $*$ & $* *$ & 5 \\
\hline Pellino 2014 & Italy & & $* * *$ & $*$ & $* *$ & 6 \\
\hline Hardiman 2014 & US & & $* * *$ & & $* *$ & 5 \\
\hline Tyler 2014 & US & & $* *$ & $*$ & $* *$ & 5 \\
\hline Phatak 2014 & US & & $* * *$ & $*$ & $* *$ & 6 \\
\hline Abegg 2014 & The Netherlands & & $* * *$ & $*$ & $* * *$ & 7 \\
\hline Glasgow 2014 & US & & $* * *$ & $*$ & $* * *$ & 7 \\
\hline Feroci 2013 & Italy & & $* * *$ & $*$ & $* *$ & 6 \\
\hline Parnaby 2013 & UK & & $* *$ & $* *$ & $* *$ & 6 \\
\hline Coakley 2013 & US & & $* * *$ & $*$ & $* *$ & 6 \\
\hline Gu 2013 & US & & $* * *$ & & $* *$ & 5 \\
\hline Hardt 2013 & Germany & & $* * *$ & $*$ & $* *$ & 6 \\
\hline
\end{tabular}


Table 1 (continued)

\begin{tabular}{|c|c|c|c|c|c|c|}
\hline \multirow[t]{2}{*}{ Author } & \multirow[t]{2}{*}{ Country } & \multirow{2}{*}{$\begin{array}{l}\text { Jadad score } \\
\text { Total }\end{array}$} & \multirow{2}{*}{$\begin{array}{l}\text { Newcastle quality } \\
\text { Selection (0-4) }\end{array}$} & \multicolumn{3}{|c|}{ Ottawa assessment } \\
\hline & & & & $\begin{array}{l}\text { Comparability } \\
(0-2)\end{array}$ & Outcome (0-3) & Total $(0-9)$ \\
\hline Byrne 2013 & UK & & $* *$ & & $* *$ & 4 \\
\hline Paquette 2013 & South Korea & 6.5 & & & & \\
\hline Lee S 2013 & South Korea & 6 & & & & \\
\hline Jafari 2013 & US & & $* * *$ & $*$ & $* *$ & 6 \\
\hline Akesson 2012 & Sweden & & $* * *$ & $*$ & $* * *$ & 7 \\
\hline Duff 2012 & Australia & & $* * * *$ & & $* *$ & 5 \\
\hline Nagle 2012 & US & & $* * *$ & $*$ & $* *$ & 6 \\
\hline Marsden 2012 & UK & & $* * * *$ & $*$ & $* *$ & 7 \\
\hline Messaris 2012 & US & & $* * *$ & $* *$ & $* *$ & 7 \\
\hline Chun 2012 & US & & $* * *$ & $* *$ & $* *$ & 7 \\
\hline Gessler 2012 & Sweden & & $* * *$ & $* *$ & $* * *$ & 8 \\
\hline Beck 2011 & Germany & & $* * *$ & $*$ & $* *$ & 6 \\
\hline Fajardo 2010 & US & & $* * *$ & $* *$ & $* *$ & 7 \\
\hline Telem 2010 & US & & $* * *$ & $*$ & $* *$ & 6 \\
\hline Datta 2009 & Canada & & $* * *$ & $* *$ & $* * *$ & 8 \\
\hline Kariv 2007 & US & & $* * *$ & $*$ & $* *$ & 6 \\
\hline Fowkes 2008 & UK & & $* * *$ & & $* *$ & 5 \\
\hline Schwenk 2006 & Germany & & $* *$ & & $* *$ & 4 \\
\hline Larson 2006 & US & & $* * *$ & $* *$ & $* *$ & 7 \\
\hline Garcia-Botello 2004 & Spain & & $* * * *$ & $* *$ & $* *$ & 8 \\
\hline Hallbook 2002 & Sweden & & $* * *$ & $*$ & $* * *$ & 7 \\
\hline Okamoto 1995 & Japan & & $* * *$ & $*$ & $*$ & 5 \\
\hline Wexner 1993 & US & & $* * * *$ & $*$ & $*$ & 6 \\
\hline Winslet 1991 & UK & & $* * *$ & * & $* *$ & 6 \\
\hline
\end{tabular}

*represents one point

readmission, dehydration was the reason for readmission in $26 \%\left(95 \%\right.$ CI $\left.0.17-0.38, I^{2}=97 \%, \tau^{2}=1.38 p<0.01\right)$ of patients (Figure S1) [1, 2, 7, 11, 18-20, 23, 25, 26, 41, $44-46,54,55,58,60,61,63,64,66]$.

Other indications for readmission within 30 days were reported in 15 studies (Table 3 and Fig. 4) [1, 2, 11, 23, 25, 36, 44-46, 54, 55, 58, 61, 64, 66] and Kim et al. were removed from this section of the analysis, because more than half of the indications for readmission were unknown [2]. Dehydration was again the most common indication for readmission, with a pooled incidence of $5 \%(95 \% \mathrm{CI}$, $\left.0.02-0.14, I^{2}=98 \%, \tau^{2}=3.76 p<0.01\right)$. Other indications for admission included stoma outlet issues in $4 \%(95 \%$ CI $\left.0.02-0.08, I^{2}=89 \%, \tau^{2}=0.98 p<0.01\right)$ and infection (excluding anastomotic leaks) in 4\% (95\% CI 0.02-0.09, $\left.I^{2}=96 \%, \tau^{2}=1.41 p<0.01\right)($ Figure $\mathrm{S} 2)$.

\section{Readmission with 60 days}

Readmission within 60 days of ileostomy creation was reported in 6 studies [3, 22, 32, 39, 49, 67]. Dehydration led to readmission in $10 \%$ (95\% CI $0.08-0.12, I^{2}=39 \%$, $\left.\tau^{2}=0.02 p=0.14\right)$, with the pooled proportion of all-cause readmission being $27 \%$ (95\% CI $0.21-0.34, I^{2}=88 \%$, $\tau^{2}=0.15 p<0.01$ ) (Figures S3, S4). Dehydration was the indication for readmission in $40 \%$ of all patients admitted during this timeframe $\left(95 \%\right.$ CI $0.34-0.47, I^{2}=38 \%, \tau^{2}=0.04$ $p=0.15)$, Figure S5.

Of the five papers reporting on other indications for readmission, Figure S6 [3, 22, 32, 39, 67], four mentioned dehydration as the leading cause [22, 32, 39, 67]. Other frequent indications included infection in 7\% (95\% CI 0.03-0.15, $\left.I^{2}=92 \%, \tau^{2}=0.83 p<0.01\right)$ and stoma outlet issues in $3 \%$ $\left(95 \%\right.$ CI $\left.0.03-0.04, I^{2}=0 \%, \tau^{2}=0 p=0.89\right)$, Figure S7.

\section{Readmissions between stoma creation and closure}

Eight studies reported on readmission related to dehydration between the time frame of ileostomy creation and closure (range 2-9 months) [27, 40, 47, 57, 68-70]. The pooled incidence of dehydration-related readmission during his time frame was $5 \%\left(95 \%\right.$ CI $\left.0.03-0.09, I^{2}=65 \%, \tau^{2}=0.46 p<0.01\right)$, Figure 


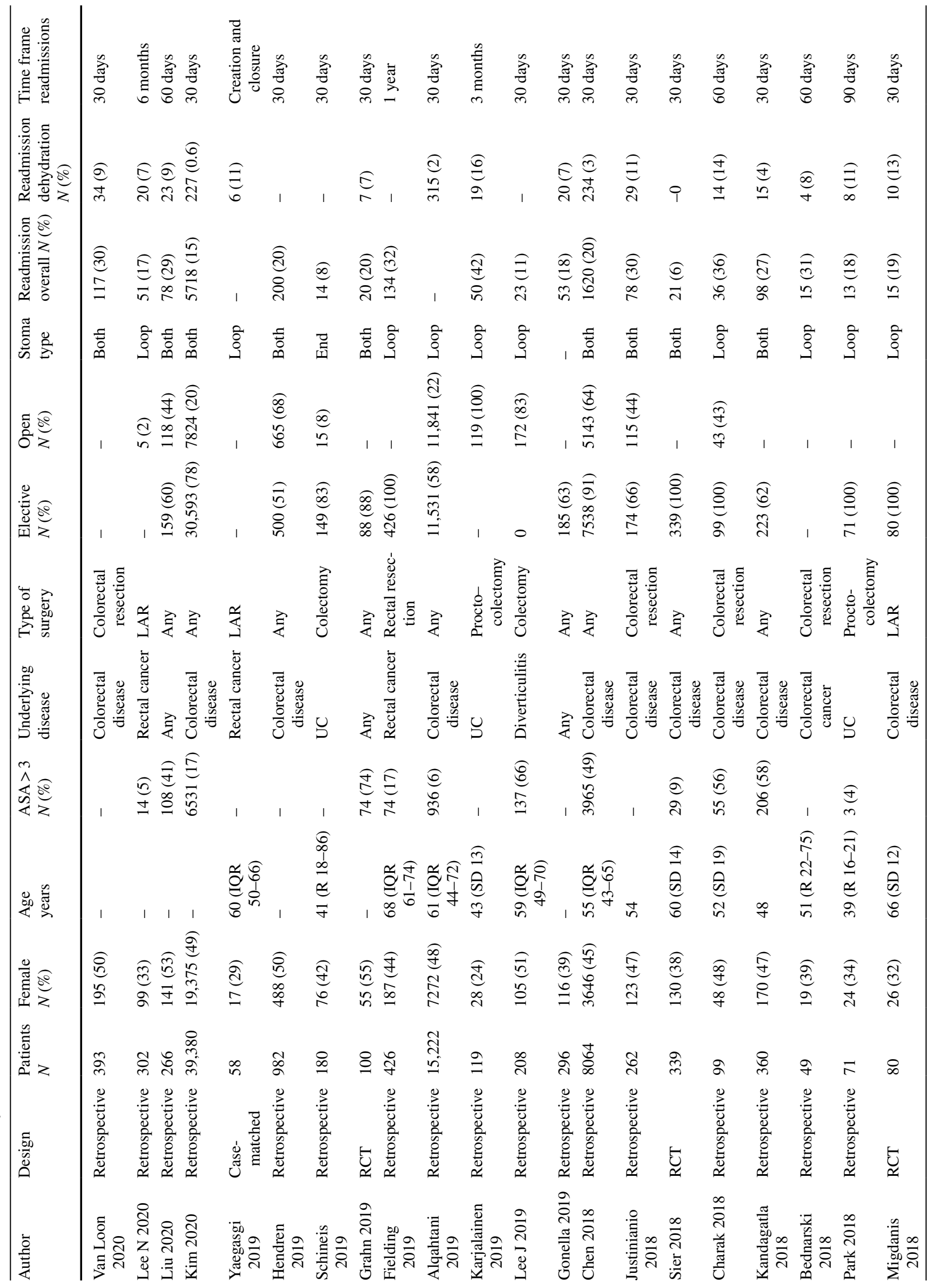




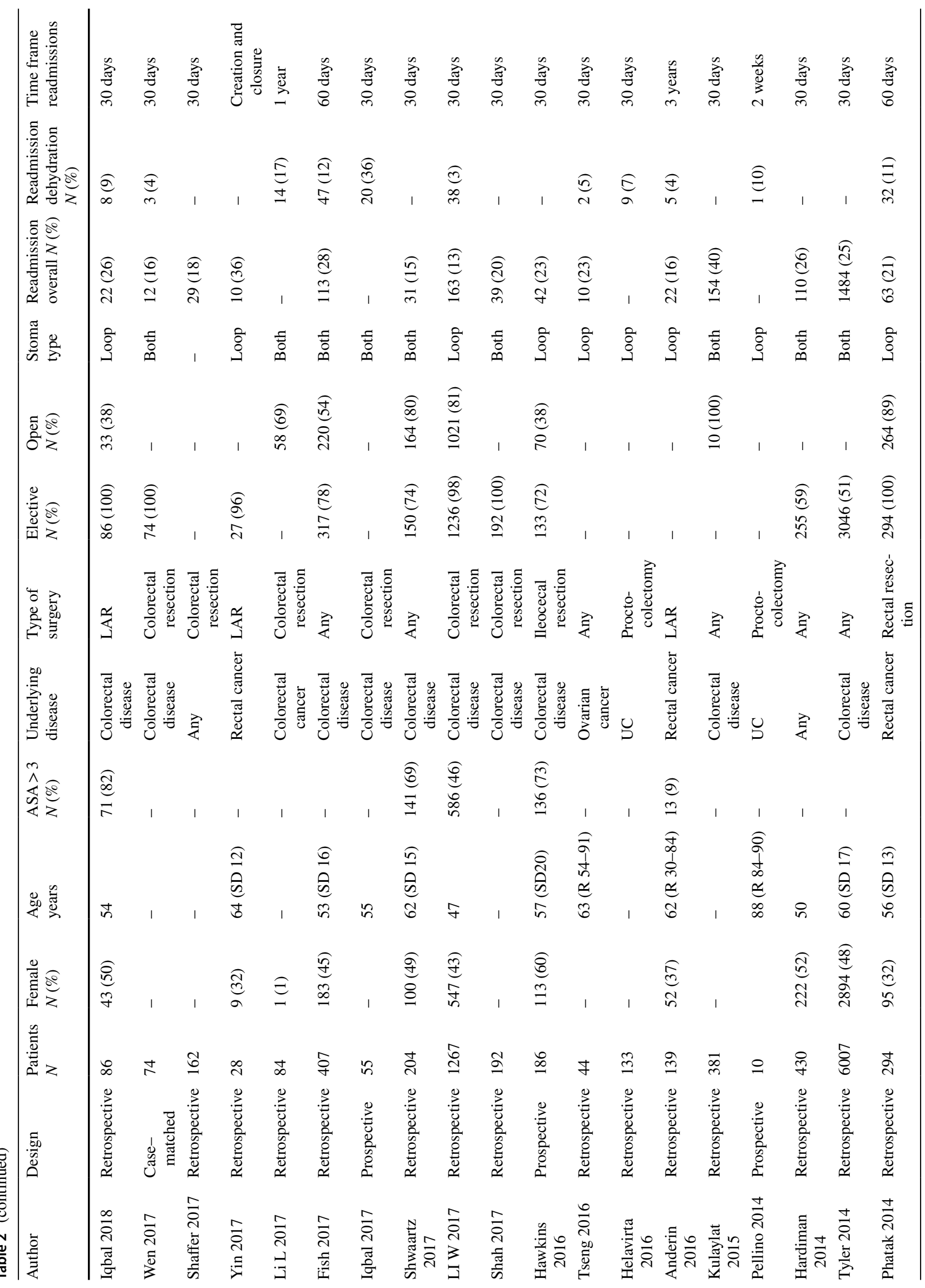




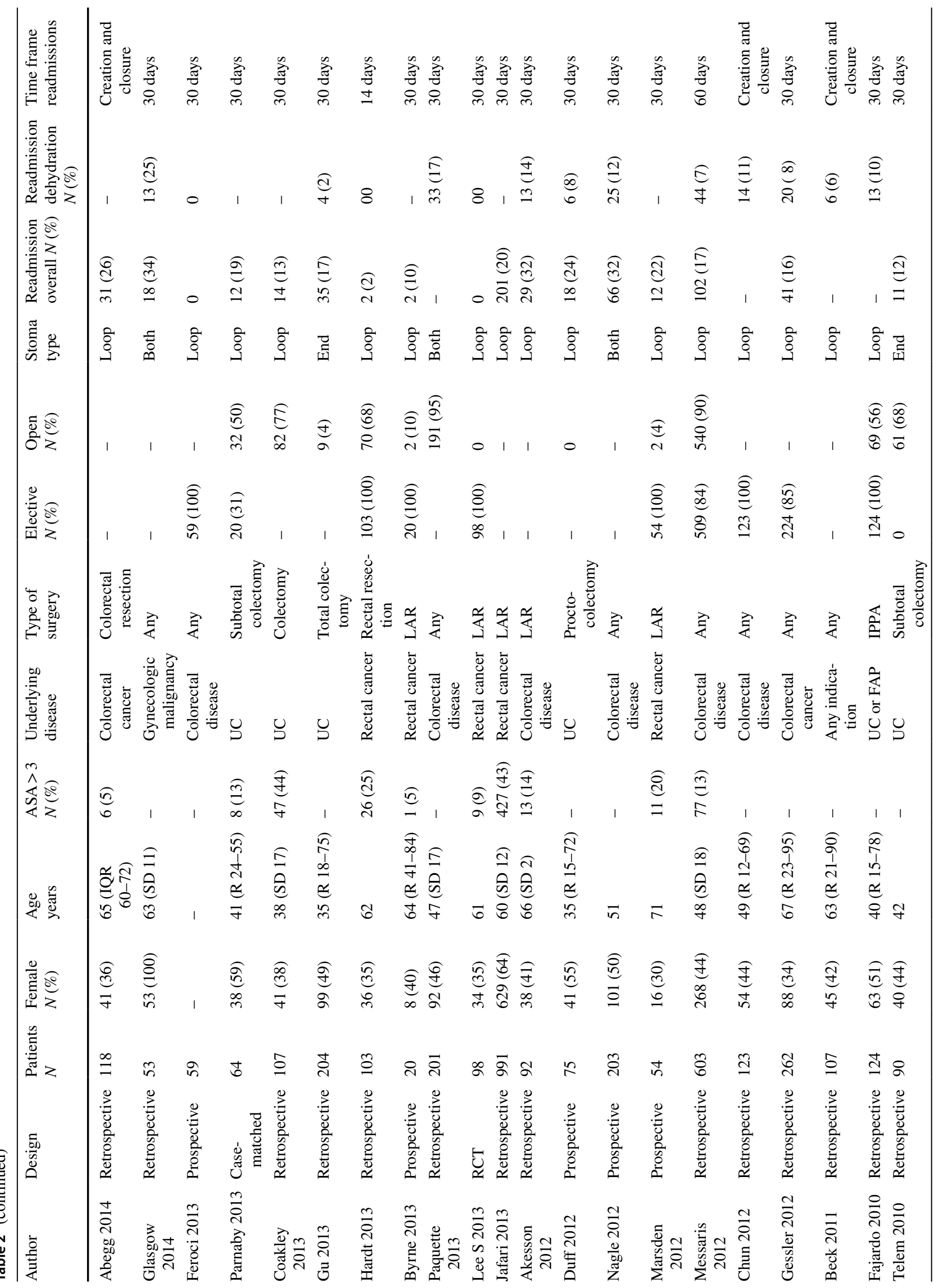




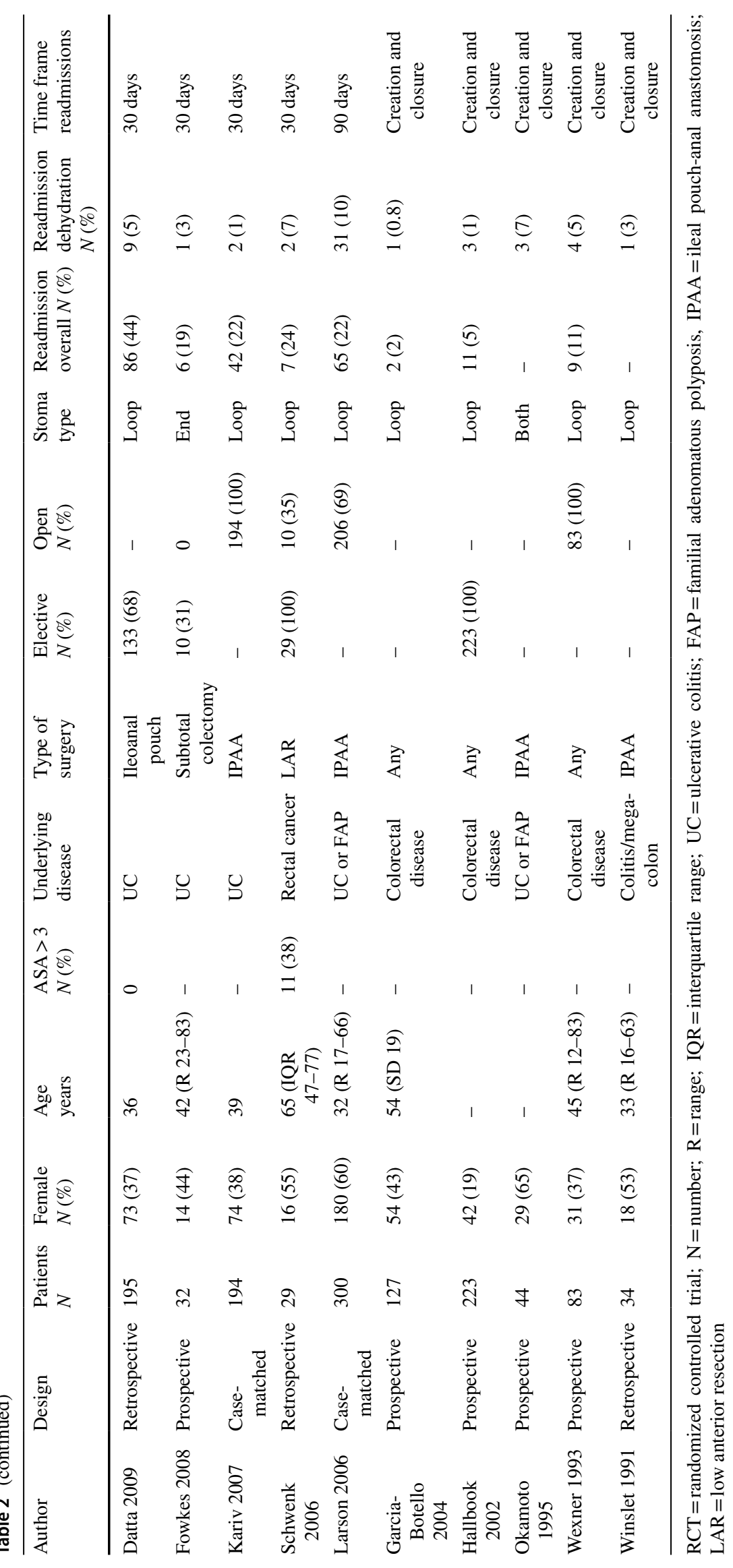




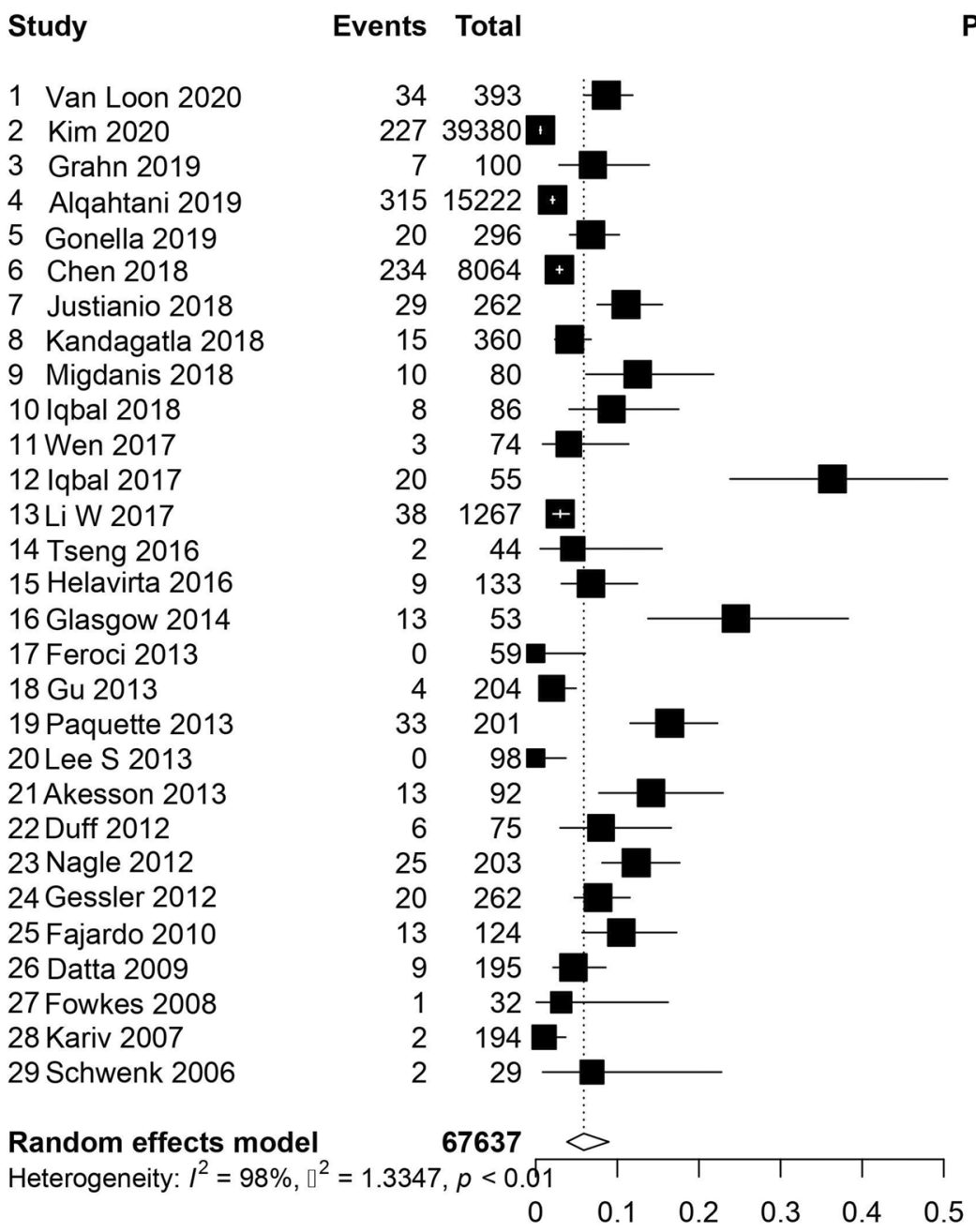

Proportion $\quad 95 \%-\mathrm{Cl}$ Weight

\begin{tabular}{|c|c|c|}
\hline 09 & {$[0.06 ; 0.12]$} & \\
\hline 0.01 & {$[0.01 ; 0.01]$} & . \\
\hline 0.07 & {$[0.03 ; 0.14]$} & 20 \\
\hline 0.02 & {$[0.02 ; 0.02]$} & \\
\hline 0.07 & {$[0.04 ; 0.10]$} & \\
\hline 0.03 & {$[0.03 ; 0.03]$} & \\
\hline 0.11 & {$[0.08 ; 0.16]$} & \\
\hline 0.04 & {$[0.02 ; 0.07]$} & \\
\hline 0.12 & {$[0.06 ; 0.22]$} & \\
\hline 0.09 & {$[0.04 ; 0.18]$} & \\
\hline 0.04 & {$[0.01 ; 0.11]$} & \\
\hline 0.36 & {$[0.24 ; 0.50]$} & \\
\hline 0.03 & {$[0.02 ; 0.04]$} & \\
\hline 0.05 & {$[0.01 ; 0.15]$} & \\
\hline 0.07 & {$[0.03 ; 0.12]$} & 3.7 \\
\hline 0.25 & {$[0.14 ; 0.38]$} & \\
\hline 0.00 & {$[0.00 ; 0.06]$} & \\
\hline 0.02 & {$[0.01 ; 0.05]$} & 3.3 \\
\hline 0.16 & {$[0.12 ; 0.22]$} & \\
\hline 0.00 & {$[0.00 ; 0.04]$} & 1.6 \\
\hline 0.14 & {$[0.08 ; 0.23]$} & \\
\hline 0.08 & {$[0.03 ; 0.17]$} & 0 \\
\hline 0.12 & {$[0.08 ; 0.18]$} & \\
\hline 0.08 & {$[0.05 ; 0.12]$} & 3.8 \\
\hline 0.10 & {$[0.06 ; 0.17]$} & 3.7 \\
\hline 0.05 & {$[0.02 ; 0.09]$} & \\
\hline 0.03 & {$[0.00 ; 0.16]$} & 2.2 \\
\hline 0.01 & {$[0.00 ; 0.04]$} & 2.9 \\
\hline 0.07 & {$[0.01 ; 0.23]$} & \\
\hline
\end{tabular}

Fig. 2 Readmission for dehydration within 30 days

S8 [40, 47, 57, 68-70]. Five studies reported on all-cause readmissions, with an incidence of $11 \%$ (95\% CI 0.04-0.26, $\left.I^{2}=92 \%, \tau^{2}=1.25 p<0.01\right)$, Figure S9 $[27,47,57,70]$. Of all readmissions, dehydration was the indication in 37\% (95\% CI $\left.0.19-0.59, I^{2}=0 \%, \tau^{2}=0 p=0.67\right)$, Figure S10 [47, 57, 70].

Of the 3 papers reporting specific indications for readmission during this time frame $[47,57,70], 2 \%$ (95\% CI $0.01-0.06, I^{2}=53 \%, \tau^{2}=0.49 p=0.12$ ) were admitted for dehydration, $2 \%$ (95\% CI $0.01-0.04, I^{2}=0 \%, \tau^{2}=0 p=0.45$ ) for stoma outlet problems, and $1 \%\left(95 \%\right.$ CI $0-0.02, I^{2}=0 \%$, $\tau^{2}=0 p=0.58$ ) for infection (Figure S11).

\section{Duration of readmission}

Ten studies reported on duration of readmission, as summarised in Table 4. Four studies reported specifically on admission for dehydration within 30 days with duration of readmission ranging from 2.5 to 6 days $[6,8,11,20]$. Five studies reported on all-cause readmission, with duration ranging from 3 to 9 days [1, 11, 20, 25, 44]. In the remaining studies, duration of readmission within 60 days or between stoma creation and closure ranged from 5 to 9.5 days $[3,57,67]$.

\section{Cost of readmission for dehydration}

Two studies reported readmission due to dehydration within 30 days of stoma creation, with a cost ranging between $\$ 2750$ and $\$ 5924$ per patient $[6,8]$. If there was additional renal failure costs increased to $\$ 9107$ [8]. After implementation of an ileostomy education and management protocol, one study reported a reduction in the number of readmissions specifically for dehydration from 65 to $16 \%$, resulting in a mean costs saving of $\$ 63,821(\$ 25,037-\$ 88,858)$ per year [6]. In the same hospital, the average cost of readmission for any cause was $\$ 13,839$ per patient [25].

Shaffer et al. reported a total cost of $\$ 4,520$ per patient for readmission within 30 days for any indication. After 


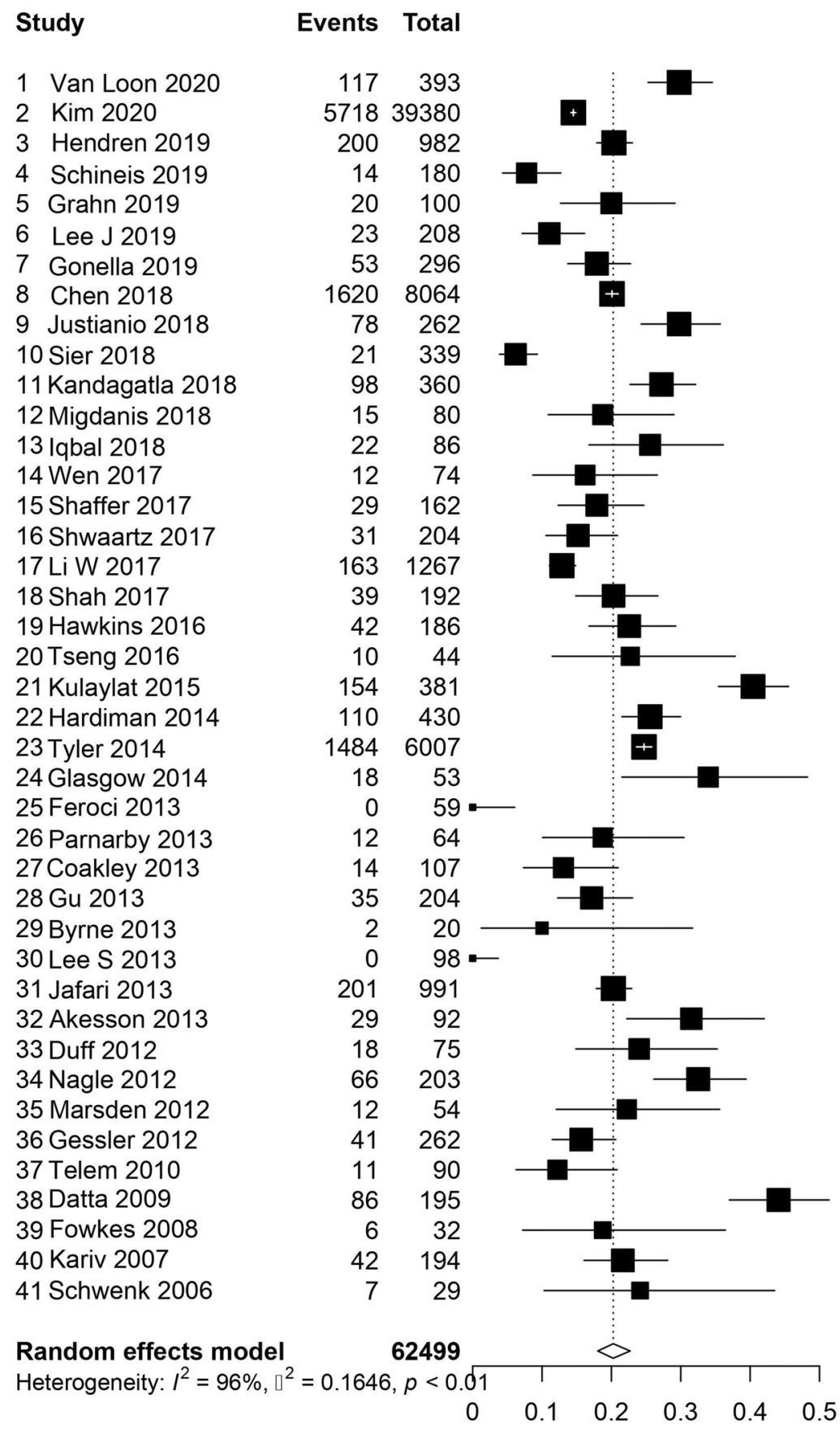

Proportion $\quad 95 \%-\mathrm{Cl}$ Weight

$\begin{array}{ll}0.30[0.25 ; 0.35] & 3.1 \% \\ 0.15[0.14 ; 0.15] & 3.3 \% \\ 0.20[0.18 ; 0.23] & 3.2 \% \\ 0.08[0.04 ; 0.13] & 2.2 \% \\ 0.20[0.13 ; 0.29] & 2.4 \% \\ 0.11[0.07 ; 0.16] & 2.5 \% \\ 0.18[0.14 ; 0.23] & 2.9 \% \\ 0.20[0.19 ; 0.21] & 3.3 \% \\ 0.30[0.24 ; 0.36] & 3.0 \% \\ 0.06[0.04 ; 0.09] & 2.5 \% \\ 0.27[0.23 ; 0.32] & 3.0 \% \\ 0.19[0.11 ; 0.29] & 2.2 \% \\ 0.26[0.17 ; 0.36] & 2.4 \% \\ 0.16[0.09 ; 0.27] & 2.1 \% \\ 0.18[0.12 ; 0.25] & 2.6 \% \\ 0.15[0.11 ; 0.21] & 2.7 \% \\ 0.13[0.11 ; 0.15] & 3.2 \% \\ 0.20[0.15 ; 0.27] & 2.8 \% \\ 0.23[0.17 ; 0.29] & 2.8 \% \\ 0.23[0.11 ; 0.38] & 1.8 \% \\ 0.40[0.35 ; 0.46] & 3.1 \% \\ 0.26[0.22 ; 0.30] & 3.1 \% \\ 0.25[0.24 ; 0.26] & 3.3 \% \\ 0.34[0.22 ; 0.48] & 2.2 \% \\ 0.00[0.00 ; 0.06] & 0.2 \% \\ 0.19[0.10 ; 0.30] & 2.0 \% \\ 0.13[0.07 ; 0.21] & 2.2 \% \\ 0.17[0.12 ; 0.23] & 2.7 \% \\ 0.10[0.01 ; 0.32] & 0.8 \% \\ 0.00[0.00 ; 0.04] & 0.2 \% \\ 0.20[0.18 ; 0.23] & 3.2 \% \\ 0.32[0.22 ; 0.42] & 2.5 \% \\ 0.24[0.15 ; 0.35] & 2.3 \% \\ 0.33[0.26 ; 0.39] & 2.9 \% \\ 0.22[0.12 ; 0.36] & 2.0 \% \\ 0.16[0.11 ; 0.21] & 2.8 \% \\ 0.12[0.06 ; 0.21] & 2.0 \% \\ 0.44[0.37 ; 0.51] & 2.9 \% \\ 0.19[0.07 ; 0.36] & 1.5 \% \\ 0.22[0.16 ; 0.28] & 2.8 \% \\ 0.24[0.10 ; 0.44] & 1.5 \% \\ & \\ 0\end{array}$

$0.20[0.18 ; 0.23] 100.0 \%$

Fig. 3 Overall readmission within 30 days

implementation of an intervention programme to improve monitoring, these costs were reduced to $\$ 508$ per patient [5].

Tyler et al. reported a mean associated charge for readmission of $\$ 33,363$ (SD, $\$ 89,396$ ) for readmissions within 30 days after a colorectal resection. In patients with an ileostomy, acute renal failure and fluid and electrolyte disorders were the second most common cause of readmission (17.4\%) after surgical complications directly related to the procedure (19.3\%) [4].

\section{Discussion}

In the present systematic review and meta-analysis, the readmission rate within 30 days after stoma creation is $20 \%$, with dehydration as the leading cause, occurring in around $6 \%$ of patients $[1-3,11,22,32,39,56,58,61]$. Other frequent indications for readmission include stoma outlet issues and infection, both occurring in around $4 \%$ of patients. The average cost of readmission is high with dehydration-related 


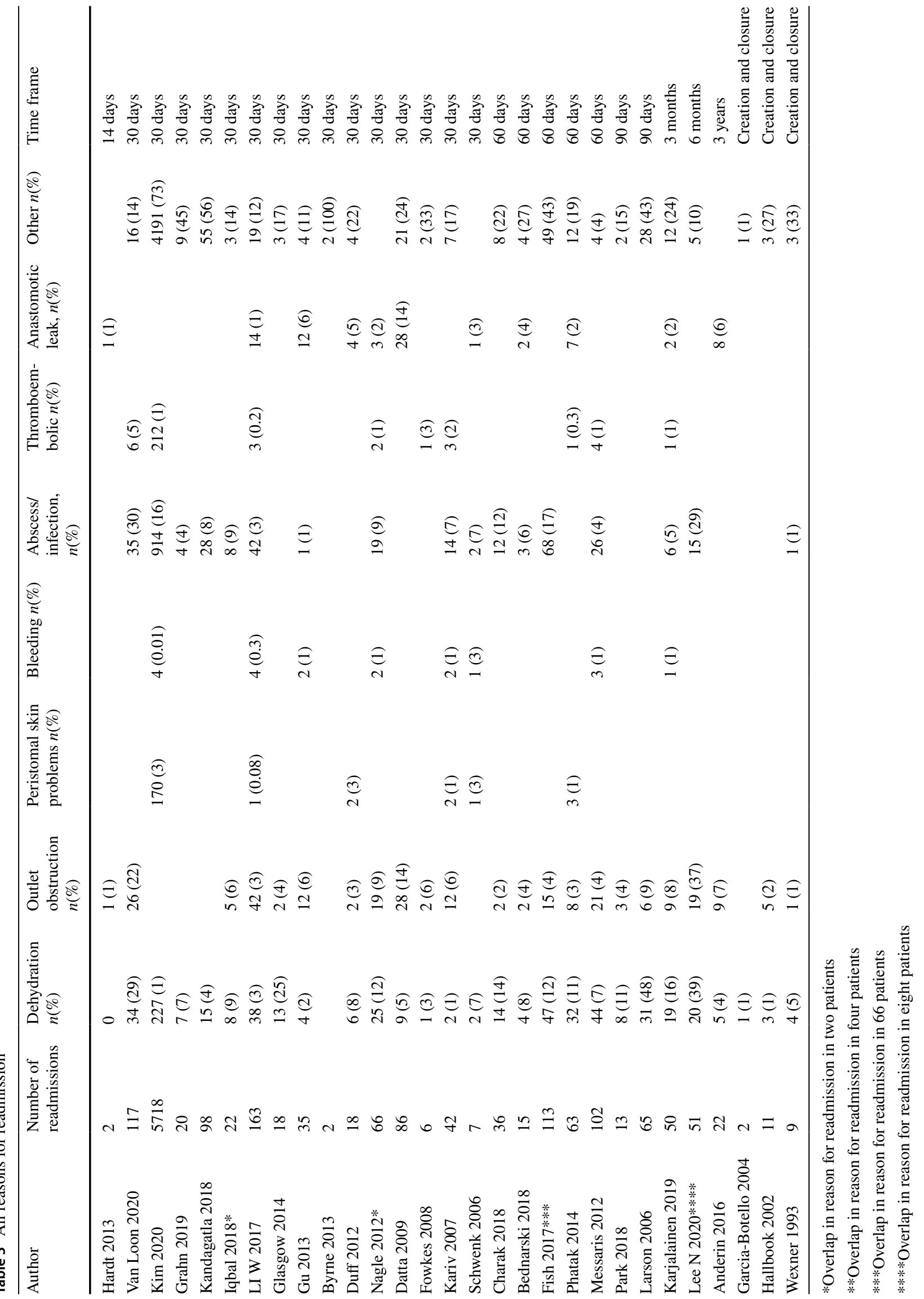


Fig. 4 Reason for readmissions: A within 30 days. B Between stoma creation and closure
A

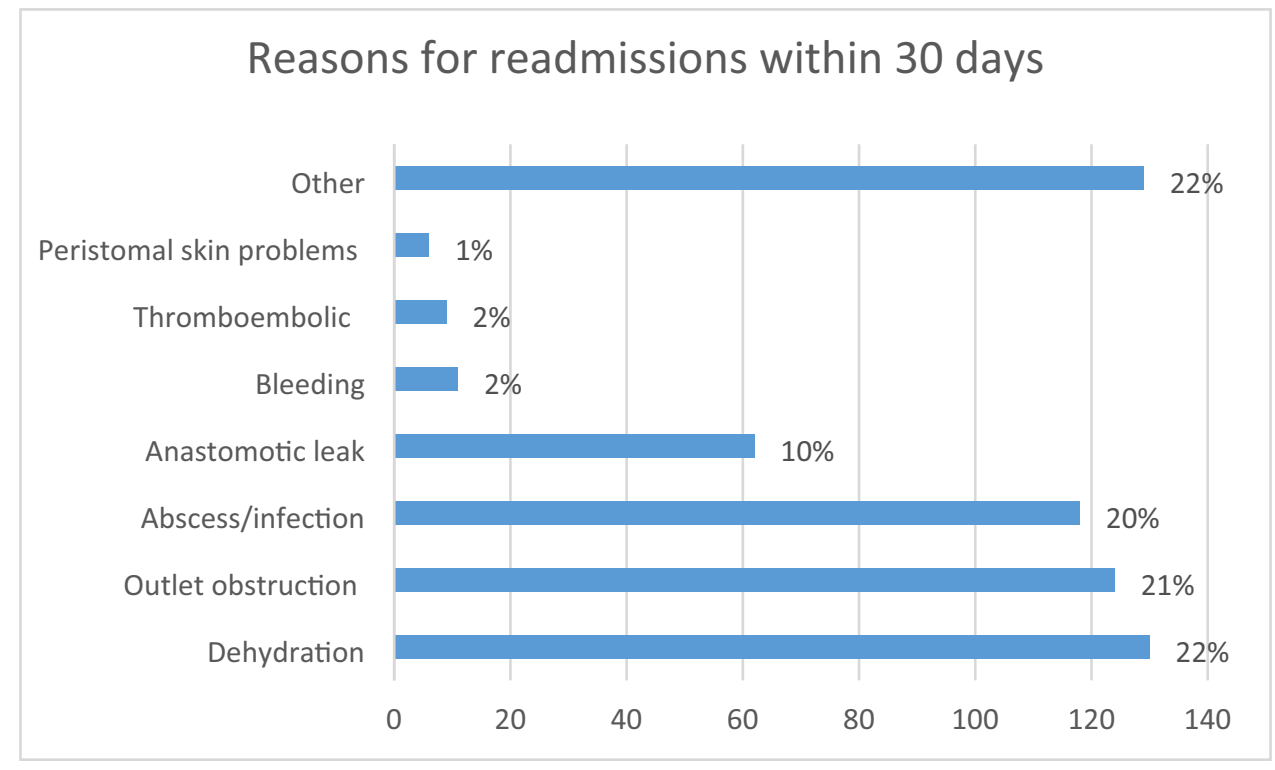

B

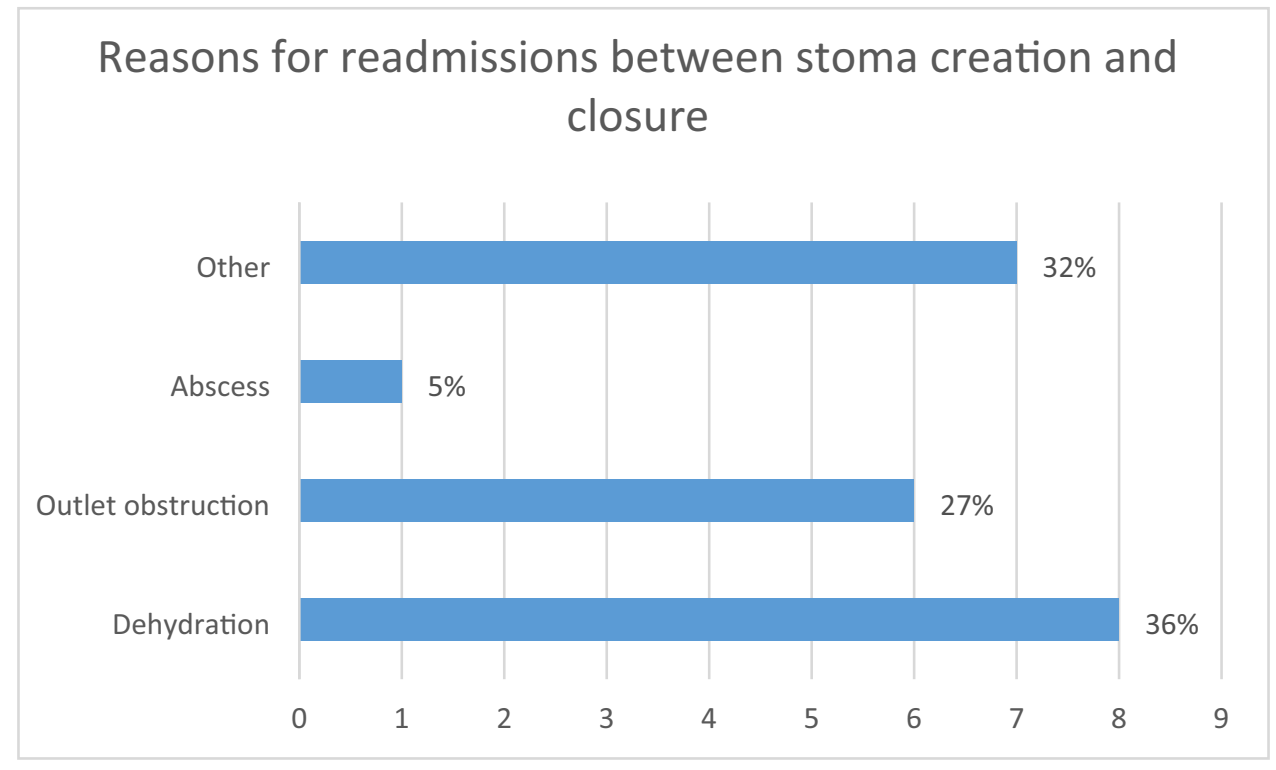

readmission costing between $\$ 2750$ and $\$ 5,924$ per patient. Thus, the creation of an ileostomy is associated with a risk of complications that frequently require costly readmission.

This high readmission rate following the creation of an ileostomy is consistent with previous published data. However, data examining the factors associated with readmission are still limited to small cohorts, single institutions, or are from reports often of poor quality $[1,2,11]$. Nonetheless dehydration, stoma outlet obstruction, and infection have been cited repeatedly as the most frequent causes.

Dehydration is most common in the early post-operative period, with the highest incidence of reduced kidney function within the first 3-6 months after surgery [48, 63, 68,
69]. Some authors report that estimated glomerular filtration rate (eGFR) values post-closure closely resemble the normal preoperative situation [69]. Others have shown a significant reduction in eGFR after ileostomy creation which remains present up to 12 months after ileostomy closure $[48,70]$. Fielding et al. found that a decline in kidney function after ileostomy creation resulted in an increased risk of severe chronic kidney disease $[\mathrm{CKD}] \geq 3$, OR 6.89 (95\% CI 4.44-10.8, $p<0.0001$ ) [48]. Dehydration after creation of an ileostomy may therefore have a significant impact on patient morbidity.

Risk factors for dehydration include: stoma output more than $1 \mathrm{~L}$ at discharge [20], the presence of comorbidity [16, 
Table 4 Duration of readmissions

\begin{tabular}{lccccc}
\hline Study & $\begin{array}{l}\text { Readmissions } \\
\text { overall } \\
N(\%)\end{array}$ & $\begin{array}{l}\text { Duration of readmission } \\
\text { overall (days) }\end{array}$ & $\begin{array}{l}\text { Readmissions } \\
\text { dehydration } \\
N(\%)\end{array}$ & $\begin{array}{l}\text { Duration readmission } \\
\text { dehydration (days) }\end{array}$ & $\begin{array}{l}\text { Time frame readmission } \\
\text { (days) }\end{array}$ \\
\hline Grahn 2019 & $20(20)$ & 4.7 (no range) & $7(7)$ & - & 30 days \\
Justinianio 2018 & $78(30)$ & $6($ IQR 3-11) & $29(11)$ & 6 (IQR 4-10) & 30 days \\
Iqbal 2018 & $22(26)$ & $5($ IQR 13-31) & $8(9)$ & - & 30 days \\
Fish 2017 & $113(28)$ & 5 (IQR 2-7) & $47(12)$ & 4 (no range) & 60 days \\
Iqbal 2017 & & & $20(36)$ & 4.2 & 30 days \\
Li W 2017 & $163(13)$ & 3 (rang 1-6) & $38(3)$ & - & 30 days \\
Abegg 2014 & $32(26)$ & 9.5 (SD 6.6) & $16(14)$ & 2.4 (range 1-7) & 30 days \\
Paquette 2013 & & $33(17)$ & & 30 days \\
Datta 2009 & $86(44)$ & 9.1 (no range) & & Creation and closure \\
Wexner 1993 & $9(11)$ & 5.2 (range 2-11) & $4(5)$ & and closure \\
\hline
\end{tabular}

$I Q R$ interquartile range

18], a higher American Society of Anesthesiologists (ASA) classification [2, 19, 23], older age [8, 19, 20], smoking [16], hypertension [19], diabetes [2, 16], use of diuretics [20, 22, $39]$, and chemotherapy $[11,20]$. The influence of gender is unclear. One study reported that female gender was associated with an increased risk for readmission for dehydration (OR 1.59) [19], and another report showed that men were more likely to be readmitted for this reason (OR 3.18) [20]. Some consider enhanced recovery after surgery (ERAS) may lead to a higher rate of readmission, but from the limited evidence available, this has not been confirmed [33, 35-37, $46,55]$. In any case, such programmes should focus on minimizing post-operative complications, preparing patients for discharge, and arranging adequate outpatient support.

Readmissions are costly and may be avoidable to some extent. This is particularly the case for dehydration, since better monitoring and timely intervention might prevent extensive fluid loss. Improved inpatient coaching and outpatient follow-up care have been shown to reduce readmission $[1,6,18,30,64]$. Despite attempts by others to introduce such programmes readmission rates remain high in some of the studies $[6,66]$. Many of these studies had very small sample sizes [1, 6], and the reduction of readmissions after implementation of the protocol did not always reach a statistically significant level $[1,30]$. Therefore, from these data, post-operative care pathways may offer a solution to the problem, but there is a need for further high-quality research to standardize the approach.

There are some limitations to this review. In most studies, readmission rates were not the primary outcome of the study. This might have led to under-reporting. There was significant heterogeneity between the different studies, making the results prone to information bias. This heterogeneity can partly be attributed to the variety of ileostomy indications in different patient populations, and the time span of 30 years in this systematic review which might include changes in indication and management of an ileostomy. In addition, the definition of dehydration and the method of diagnosis varied; for example in some studies, coded diagnoses were used to identify patients with dehydration. In this review, the majority of the ileostomies were created in an elective setting [7, 21, 22, 24-26, $29,32,33,35,36,38,40,42,46-48,59]$. This might have led to an underestimate readmission as emergency surgery is known to increase complications. Furthermore, there were only a few reports on preoperative kidney function, or other factors that might contribute to the risk of dehydration such as an additional small bowel resection or post-operative re-intervention. Finally, the reason for readmission within 30 days was unknown in $62 \%$ of the largest cohort included in our meta-analysis [2].

\section{Conclusions}

One out of five patients is readmitted after creation of an ileostomy. Dehydration is the leading cause for these readmissions, occurring in one-third of patients within 30 days. This comes with high health care costs. Better monitoring, patient awareness, and preventive measures are required.

Supplementary Information The online version contains supplementary material available at https://doi.org/10.1007/s10151-022-02580-6.

\section{Declarations}

Conflict of interest The authors declare that they have no conflict of interest. 
Ethical approval This article does not contain any studies with human participants or animals performed by any of the authors.

Informed consent For this type of study formal consent is not required.

Open Access This article is licensed under a Creative Commons Attribution 4.0 International License, which permits use, sharing, adaptation, distribution and reproduction in any medium or format, as long as you give appropriate credit to the original author(s) and the source, provide a link to the Creative Commons licence, and indicate if changes were made. The images or other third party material in this article are included in the article's Creative Commons licence, unless indicated otherwise in a credit line to the material. If material is not included in the article's Creative Commons licence and your intended use is not permitted by statutory regulation or exceeds the permitted use, you will need to obtain permission directly from the copyright holder. To view a copy of this licence, visit http://creativecommons.org/licenses/by/4.0/.

\section{References}

1. Grahn SW, Lowry AC, Osborne MC, Melton GB, Gaertner WB, Vogler SA et al (2019) System-wide improvement for transitions after ileostomy surgery: can intensive monitoring of protocol compliance decrease readmissions? A randomized trial. Dis Colon Rectum 62(3):363-370

2. Kim NE, Hall JF (2020) Risk factors for readmission after ileostomy creation: an NSQIP database study. J Gastrointest Surg 25:1010

3. Fish DRMC, Garcia-Aguilar JE et al (2017) Readmission after ileostomy creation: retrospective review of a common and significant event. Ann Surg 265(2):379-387

4. Tyler JA, Fox JP, Dharmarajan S, Silviera ML, Hunt SR, Wise PE et al (2014) Acute health care resource utilization for ileostomy patients is higher than expected. Dis Colon Rectum 57(12):1412-1420

5. Shaffer VO, Owi T, Kumarusamy MA, Sullivan PS, Srinivasan JK, Maithel SK et al (2017) Decreasing hospital readmission in ileostomy patients: results of novel pilot program. J Am Coll Surg 224(4):425-430

6. Iqbal A, Raza A, Huang E, Goldstein L, Hughes SJ, Tan SA (2017) Cost effectiveness of a novel attempt to reduce readmission after ileostomy creation. JSLS. https://doi.org/10.4293/JSLS. 2016.00082

7. Migdanis A, Koukoulis G, Mamaloudis I, Baloyiannis I, Migdanis I, Kanaki M et al (2018) Administration of an oral hydration solution prevents electrolyte and fluid disturbances and reduces readmissions in patients with a diverting ileostomy after colorectal surgery: a prospective, randomized controlled trial. Dis Colon Rectum 61(7):840-846

8. Paquette IM, Solan P, Rafferty JF, Ferguson MA, Davis BR (2013) Readmission for dehydration or renal failure after ileostomy creation. Dis Colon Rectum 56(8):974-979

9. Moher D, Liberati A, Tetzlaff J, Altman DG (2010) Preferred reporting items for systematic reviews and meta-analyses: the PRISMA statement. Int J Surg 8(5):336-341

10. Palevsky PM, Liu KD, Brophy PD, Chawla LS, Parikh CR, Thakar CV et al (2013) KDOQI US commentary on the 2012 KDIGO clinical practice guideline for acute kidney injury. Am J Kidney Dis 61(5):649-672

11. Li W, Stocchi L, Cherla D, Liu G, Agostinelli A, Delaney CP et al (2017) Factors associated with hospital readmission following diverting ileostomy creation. Tech Coloproctol 21(8):641-648
12. Wells G, Shea B, O'Connell J (2014) The Newcastle-Ottawa scale (NOS) for assessing the quality of nonrandomised studies in metaanalyses. Ottawa Health Research Institute, Ottawa

13. Jadad AR, Moore RA, Carroll D, Jenkinson C, Reynolds DJ, Gavaghan DJ et al (1996) Assessing the quality of reports of randomized clinical trials: is blinding necessary? Control Clin Trials 17(1):1-12

14. Hendren S, Vu J, Suwanabol P, Kamdar N, Hardiman K (2019) Hospital variation in readmissions and visits to the emergency department following ileostomy surgery. J Gastrointest Surg. https://doi.org/10.1007/s11605-019-04407-6

15. Schineis C, Lehmann KS, Lauscher JC, Beyer K, Hartmann L, Margonis GA et al (2019) Colectomy with ileostomy for severe ulcerative colitis-postoperative complications and risk factors. Int J Colorectal Dis. https://doi.org/10.1007/s00384-019-03494-w

16. Alqahtani M, Garfinkle R, Zhao K, Vasilevsky CA, Morin N, Ghitulescu G et al (2019) Can we better predict readmission for dehydration following creation of a diverting loop ileostomy: development and validation of a prediction model and webbased risk calculator. Surg Endosc. https://doi.org/10.1007/ s00464-019-07069-2

17. Lee JM, Bai PCJ, El Hechi M, Kongkaewpaisan N, Bonde A, Mendoza AE et al (2019) Hartmann's procedure vs primary anastomosis with diverting loop ileostomy for acute diverticulitis: nationwide analysis of 2,729 emergency surgery patients. J Am Coll Surg 229(1):48-55

18. Gonella F, Valenti A, Massucco P, Russolillo N, Mineccia M, Fontana AP et al (2019) A novel patient-centered protocol to reduce hospital readmissions for dehydration after ileostomy. Updates Surg 71(3):515-521

19. Chen SY, Stem M, Cerullo M, Canner JK, Gearhart SL, Safar $B$ et al (2018) Predicting the risk of readmission from dehydration after ileostomy formation: the dehydration readmission after ileostomy prediction score. Dis Colon Rectum 61(12):1410-1417

20. Justiniano CF, Temple LK, Swanger AA, Xu Z, Speranza JR, Cellini $C$ et al (2018) Readmissions with dehydration after ileostomy creation: rethinking risk factors. Dis Colon Rectum 61(11):1297-1305

21. Sier MF, Wisselink DD, Ubbink DT, Oostenbroek RJ, Veldink GJ, Lamme B et al (2018) Randomized clinical trial of intracutaneously versus transcutaneously sutured ileostomy to prevent stoma-related complications (ISI trial). Br J Surg 105(6):637-644

22. Charak G, Kuritzkes BA, Al-Mazrou A, Suradkar K, Valizadeh N, Lee-Kong SA et al (2018) Use of an ACE inhibitor or angiotensin receptor blocker is a major risk factor for dehydration requiring readmission in the setting of a new ileostomy. Int J Colorectal Dis 33(3):311-316

23. Kandagatla P, Nikolian VC, Matusko N, Mason S, Regenbogen SE, Hardiman KM (2018) Patient-reported outcomes and readmission after ileostomy creation in older adults. Am Surg 84(11):1814-1818

24. Park J, Gessler B, Block M, Angenete E (2018) Complications and morbidity associated with loop ileostomies in patients with ulcerative colitis. Scand J Surg 107(1):38-42

25. Iqbal A, Sakharuk I, Goldstein L, Tan SA, Qiu P, Li Z et al (2018) Readmission after elective ileostomy in colorectal surgery is predictable. JSLS. https://doi.org/10.4293/JSLS.2018.00008

26. Wen Y, Jabir MA, Keating M, Althans AR, Brady JT, Champagne BJ et al (2017) Alvimopan in the setting of colorectal resection with an ostomy: to use or not to use? Surg Endosc 31(9):3483-3488

27. Yin TC, Tsai HL, Yang PF, Su WC, Ma CJ, Huang CW et al (2017) Early closure of defunctioning stoma increases complications related to stoma closure after concurrent chemoradiotherapy and low anterior resection in patients with rectal cancer. World $\mathbf{J}$ Surg Oncol 15(1):80 
28. Shwaartz C, Fields AC, Prigoff JG, Aalberg JJ, Divino CM (2017) Should patients with obstructing colorectal cancer have proximal diversion? Am J Surg 213(4):742-747

29. Shah PM, Johnston L, Sarosiek B, Harrigan A, Friel CM, Thiele $\mathrm{RH}$ et al (2017) Reducing readmissions while shortening length of stay: the positive impact of an enhanced recovery protocol in colorectal surgery. Dis Colon Rectum 60(2):219-227

30. Hardiman KM, Reames CD, McLeod MC, Regenbogen SE (2016) Patient autonomy-centered self-care checklist reduces hospital readmissions after ileostomy creation. Surgery 160(5):1302-1308

31. Hawkins AT, Dharmarajan S, Wells KK, Krishnamurty DM, Mutch MG, Glasgow SC (2016) Does diverting loop ileostomy improve outcomes following open ileo-colic anastomoses? A nationwide analysis. J Gastrointest Surg 20(10):1738-1743

32. Phatak UR, Kao LS, You YN, Rodriguez-Bigas MA, Skibber JM, Feig BW et al (2014) Impact of ileostomy-related complications on the multidisciplinary treatment of rectal cancer. Ann Surg Oncol 21(2):507-512

33. Feroci F, Lenzi E, Baraghini M, Garzi A, Vannucchi A, Cantafio $S$ et al (2013) Fast-track surgery in real life: how patient factors influence outcomes and compliance with an enhanced recovery clinical pathway after colorectal surgery. Surg Laparosc Endosc Percutan Tech 23(3):259-265

34. Parnaby CN, Ramsay G, Macleod CS, Hope NR, Jansen JO, McAdam TK (2013) Complications after laparoscopic and open subtotal colectomy for inflammatory colitis: a case-matched comparison. Colorectal Dis 15(11):1399-1405

35. Hardt J, Schwarzbach M, Hasenberg T, Post S, Kienle P, Ronellenfitsch U (2013) The effect of a clinical pathway for enhanced recovery of rectal resections on perioperative quality of care. Int J Colorectal Dis 28(7):1019-1026

36. Byrne BE, Branagan G, Chave HS (2013) Unselected rectal cancer patients undergoing low anterior resection with defunctioning ileostomy can be safely managed within an enhanced recovery programme. Tech Coloproctol 17(1):73-78

37. Lee SM, Kang SB, Jang JH, Park JS, Hong S, Lee TG et al (2013) Early rehabilitation versus conventional care after laparoscopic rectal surgery: a prospective, randomized, controlled trial. Surg Endosc 27(10):3902-3909

38. Marsden MR, Conti JA, Zeidan S, Flashman KG, Khan JS, O'Leary DP et al (2012) The selective use of splenic flexure mobilization is safe in both laparoscopic and open anterior resections. Colorectal Dis 14(10):1255-1261

39. Messaris E, Sehgal R, Deiling S, Koltun WA, Stewart D, McKenna $\mathrm{K}$ et al (2012) Dehydration is the most common indication for readmission after diverting ileostomy creation. Dis Colon Rectum 55(2):175-180

40. Chun LJ, Haigh PI, Tam MS, Abbas MA (2012) Defunctioning loop ileostomy for pelvic anastomoses: predictors of morbidity and nonclosure. Dis Colon Rectum 55(2):167-174

41. Gessler B, Haglind E, Angenete E (2012) Loop ileostomies in colorectal cancer patients-morbidity and risk factors for nonreversal. J Surg Res 178(2):708-714

42. Fajardo AD, Dharmarajan S, George V, Hunt SR, Birnbaum EH, Fleshman JW et al (2010) Laparoscopic versus open 2-stage ileal pouch: laparoscopic approach allows for faster restoration of intestinal continuity. J Am Coll Surg 211(3):377-383

43. Telem DA, Vine AJ, Swain G, Divino CM, Salky B, Greenstein AJ et al (2010) Laparoscopic subtotal colectomy for medically refractory ulcerative colitis: the time has come. Surg Endosc 24(7):1616-1620

44. Datta I, Buie WD, Maclean AR, Heine JA (2009) Hospital readmission rates after ileal pouch-anal anastomosis. Dis Colon Rectum 52(1):55-58
45. Fowkes L, Krishna K, Menon A, Greenslade GL, Dixon AR (2008) Laparoscopic emergency and elective surgery for ulcerative colitis. Colorectal Dis 10(4):373-378

46. Schwenk W, Neudecker J, Raue W, Haase O, Muller JM (2006) "Fast-track" rehabilitation after rectal cancer resection. Int J Colorectal Dis 21(6):547-553

47. Hallbook O, Matthiessen P, Leinskold T, Nystrom PO, Sjodahl $\mathrm{R}$ (2002) Safety of the temporary loop ileostomy. Colorectal Dis 4(5):361-364

48. Fielding A, Woods R, Moosvi SR, Wharton RQ, Speakman CTM, Kapur S et al (2019) Renal impairment after ileostomy formation: a frequent event with long-term consequences. Colorectal Dis. https://doi.org/10.1111/codi.14866

49. Liu C, Bhat S, O'Grady G, Bissett I (2020) Re-admissions after ileostomy formation: a retrospective analysis from a New Zealand tertiary centre. ANZ J Surg 90(9):1621-1626

50. Karjalainen EK, Mustonen HK, Lepisto AH (2019) Morbidity related to diverting ileostomy after restorative proctocolectomy in patients with ulcerative colitis. Colorectal Dis 21(6):671-678

51. Li L, Lau KS, Ramanathan V, Orcutt ST, Sansgiry S, Albo D et al (2017) Ileostomy creation in colorectal cancer surgery: risk of acute kidney injury and chronic kidney disease. J Surg Res 210:204-212

52. Kulaylat AN, Dillon PW, Hollenbeak CS, Stewart DB (2015) Determinants of 30-d readmission after colectomy. J Surg Res 193(2):528-535

53. Coakley BA, Telem D, Nguyen S, Dallas K, Divino CM (2013) Prolonged preoperative hospitalization correlates with worse outcomes after colectomy for acute fulminant ulcerative colitis. Surgery 153(2):242-248

54. Gu J, Stocchi L, Remzi F, Kiran RP (2013) Factors associated with postoperative morbidity, reoperation and readmission rates after laparoscopic total abdominal colectomy for ulcerative colitis. Colorectal Dis 15(9):1123-1129

55. Kariv Y, Delaney CP, Senagore AJ, Manilich EA, Hammel JP, Church JM et al (2007) Clinical outcomes and cost analysis of a "fast track" postoperative care pathway for ileal pouchanal anastomosis: a case control study. Dis Colon Rectum 50(2):137-146

56. Larson DW, Cima RR, Dozois EJ, Davies M, Piotrowicz K, Barnes SA et al (2006) Safety, feasibility, and short-term outcomes of laparoscopic ileal-pouch-anal anastomosis: a single institutional case-matched experience. Ann Surg 243(5):667-670

57. Wexner SD, Taranow DA, Johansen OB, Itzkowitz F, Daniel $\mathrm{N}$, Nogueras JJ et al (1993) Loop ileostomy is a safe option for fecal diversion. Dis Colon Rectum 36(4):349-354

58. Duff SE, Sagar PM, Rao M, Macafee D, El-Khoury T (2012) Laparoscopic restorative proctocolectomy: safety and critical level of the ileal pouch anal anastomosis. Colorectal Dis 14(7):883-886

59. Lee N, Lee SY, Kim CH, Kwak HD, Ju JK, Kim HR (2021) The relationship between high-output stomas, postoperative ileus, and readmission after rectal cancer surgery with diverting ileostomy. Ann Coloproctol 37(1):44-50

60. Tseng JH, Suidan RS, Zivanovic O, Gardner GJ, Sonoda Y, Levine DA et al (2016) Diverting ileostomy during primary debulking surgery for ovarian cancer: associated factors and postoperative outcomes. Gynecol Oncol 142(2):217-224

61. Glasgow MA, Shields K, Vogel RI, Teoh D, Argenta PA (2014) Postoperative readmissions following ileostomy formation among patients with a gynecologic malignancy. Gynecol Oncol 134(3):561-565

62. Jafari MD, Halabi WJ, Jafari F, Nguyen VQ, Stamos MJ, Carmichael JC et al (2013) Morbidity of diverting ileostomy for rectal cancer: analysis of the American college of surgeons 
national surgical quality improvement program. Am Surg 79(10):1034-1039

63. Akesson OSI, Lindmark G, Buchwald P (2012) Morbidity related to defunctioning loop ileostomy in low anterior resection. Int J Colorectal Dis 27(12):1619-1623

64. Nagle D, Pare T, Keenan E, Marcet K, Tizio S, Poylin V (2012) Ileostomy pathway virtually eliminates readmissions for dehydration in new ostomates. Dis Colon Rectum 55(12):1266-1272

65. Helavirta I, Huhtala H, Hyoty M, Collin P, Aitola P (2016) Restorative proctocolectomy for ulcerative colitis in 1985-2009. Scand J Surg 105(2):73-77

66. van Loon YT, Poylin VY, Nagle D, Zimmerman DDE (2020) Effectiveness of the ileostomy pathway in reducing readmissions for dehydration: does it stand the test of time? Dis Colon Rectum 63(8):1151-1155

67. Abegg RM, Brokelman W, van Bebber IP, Bosscha K, Prins HA, Lips DJ (2014) Results of construction of protective loop ileostomies and reversal surgery for colorectal surgery. Eur Surg Res 52(1-2):63-72

68. Beck-Kaltenbach N, Voigt K, Rumstadt B (2011) Renal impairment caused by temporary loop ileostomy. Int J Colorectal Dis 26(5):623-626

69. Okamoto T, Kusunoki M, Kusuhara K, Yamamura T, Utsunomiya J (1995) Water and electrolyte balance after ileal J pouch-anal anastomosis in ulcerative colitis and familial adenomatous polyposis. Int J Colorectal Dis 10(1):33-38

70. Yaegashi M, Otsuka K, Kimura T, Matsuo T, Fujii H, Sato K et al (2019) Early renal dysfunction after temporary ileostomy construction. Surg Today. https://doi.org/10.1007/ s00595-019-01938-y

Publisher's Note Springer Nature remains neutral with regard to jurisdictional claims in published maps and institutional affiliations. 